\title{
The Impact of Strenght Electromyostimulation Training on Muscle Stiffness and Blood Flow: An Exploration Using Shear Wave Elastography and Superb Microvascular Imaging
}

\author{
Orkun Akkoc', Emine Caliskan ${ }^{2, *}$ \\ ${ }^{1}$ Department of Moving and Training, Faculty of Sports Science, Istanbul Cerrahpasa University, Istanbul, Turkey \\ ${ }^{2}$ Department of Radiology, Seyhan State Hospital, Turkey
}

Copyright $\mathrm{C} 2019$ by authors, all rights reserved. Authors agree that this article remains permanently open access under the terms of the Creative Commons Attribution License 4.0 International License

\begin{abstract}
To assess the acute effect of strength exercises combined with EMS on blood flow and muscle stiffness using SMI and SWE. This prospective study included 20 participants. Subjects were divided into groups base on calisthenics strength training with EMS and without EMS. Rectus femoris (RF) blood flow was measured at rest and post-exercise with the vascularity index (\%) and stiffness was measured in $\mathrm{kPa}$ mode to compare the groups. When values are compared at rest and post-exercise, all cases had significantly increased blood flow and stiffness increase in RF post-exercise (resting mean VI [\%]: $1.42 \pm 0.58$ and post-exercise mean VI [\%]: $5.36 \pm 3.03$; resting mean stiffness $[\mathrm{kPa}]: 8.85 \pm 1.38)$ and post-exercise mean stiffness [kPa]: 10.57 1.79 ). The blood flow and stiffness values in the group with EMS and exercise had greater increases than the group with exercise without EMS ( $p=0.007, p=0.05$, respectively). Calisthenics strength training increases RF blood flow and stiffness in the acute period. SMI and SWE are beneficial and practical radiological methods that may be used to show these variations. Strength exercises using EMS may be associated with better athletic performance.
\end{abstract}

Keywords Calisthenics Training, Electromyostimulation, Muscle Blood Flow, Muscle Stiffness, Shear Wave Elastography, Superb Microvascular Imaging

\section{Introduction}

Electromyostimulation (EMS) is defined as electrical currents applied to muscle tissue and motor points $[1,2]$. EMS training has been used for treatment of some chronic diseases related with muscle condition, sports injuries and/or physical rehabilitation [3-5]. In recent years, EMS has begun to be popularly used in the fields of exercise and sports. There are many studies investigating the effect of EMS training on speed, vertical jump, strength, resistance, flexibility, aerobic and anaerobic capacities, neural adaptation, muscle activation and muscle functions [6-9].

It is stated the vascular structures and functions of physically active individuals are better compared to those of sedentary individuals [10,11]. Resistance-type exercise causes increases in the vascular lumen diameter and arterial cross-sectional area [12]. Physical inactivity is stated to cause narrowing of the arterial cross-section area $[13,14]$. Larger vascular diameter increases the amount of oxygen reaching muscles and provides better perfusion of muscles allowing the possibility of better nutrition [15]. As a result, better intramuscular blood flow provides the opportunity to produce higher levels of physical performance.

Superb microvascular imaging (SMI) is an application added to the ultrasound device and is a novel Doppler method. Compared to conventional Doppler techniques like power Doppler and color Doppler, it uses a higher frame rate and the most significant advantage of SMI is successful imaging of very fine vascular structures [16]. There is still not much information in the literature about the use of this technique for muscles.

Shear wave elastography (SWE) is a non-invasive radiological method used to measure the stiffness of tissue, that obtains a quantitative estimation of the elasticity of different tissues in the body Tissue stiffness measurements may be beneficial for the identification and treatment of a variety of disorders. However, there are limited studies investigating the effect of muscle stiffness determined with this method on athletic performance. Calisthenics training is a type of exercise using only the person's body weight. 
To the best of our knowledge, there is no study in the literature about how EMS training combined with calisthenic strength exercises affects tissue stiffness and blood flow.

The aim of this study is to assess the acute effect of calisthenics strength exercises combined with EMS on blood flow and muscle stiffness using SMI and SWE. Additionally, acute biomechanical properties induced in muscles by exercises with and without EMS were compared.

\section{Material and Methods}

\subsection{Participants}

Twenty healthy individuals (10 females and 10 males) voluntarily participated in the study. All participants were individuals involved in sports on at least 3 days per week. The study abided by the Helsinki Declaration. Subjects were given necessary information about the scope and content of the study and signed a voluntary consent form. The study received permission from the ethics committee.

\subsection{Study Design}

Before beginning the study, all participants had height and body weight measured. The stiffness and blood flow in the rectus femoris (RF), one of the quadriceps muscle group members, were measured at rest. Subjects performed calisthenic strength exercises, and immediately after exercise RF stiffness and blood flow were measured again, with the difference between the two measurements assessed. The participants were divided into 2 subgroups in the study. The first group of participants performed 3 different leg movements (squat, split squat and lunge) in 3 sets of 15 repetitions without using EMS (Fig-1). There were 30-seconds rest between sets and 1-minute rest between repetitions. The second group of participants used EMS and performed the same number of the same movements and had the same rest periods. The variations in stiffness and blood flow in the muscle were compared between the groups.

\subsection{EMS Protocol}

EMS application used a Miha Bodyex Gmbh device. An $85 \mathrm{~cm}$ long, $8 \mathrm{~cm}$ wide leg pad was placed on the center point of the thigh. Before applying electrical current, the internal surface of the leg pad was wetted with a small amount of water. The pad had current flow set to $65 \mathrm{~Hz}$ (high flow). This level of current created minimal tingling in the subject's leg. The electric current was applied to the subject during exercise, with current stopped during rest periods between sets and repetitions.

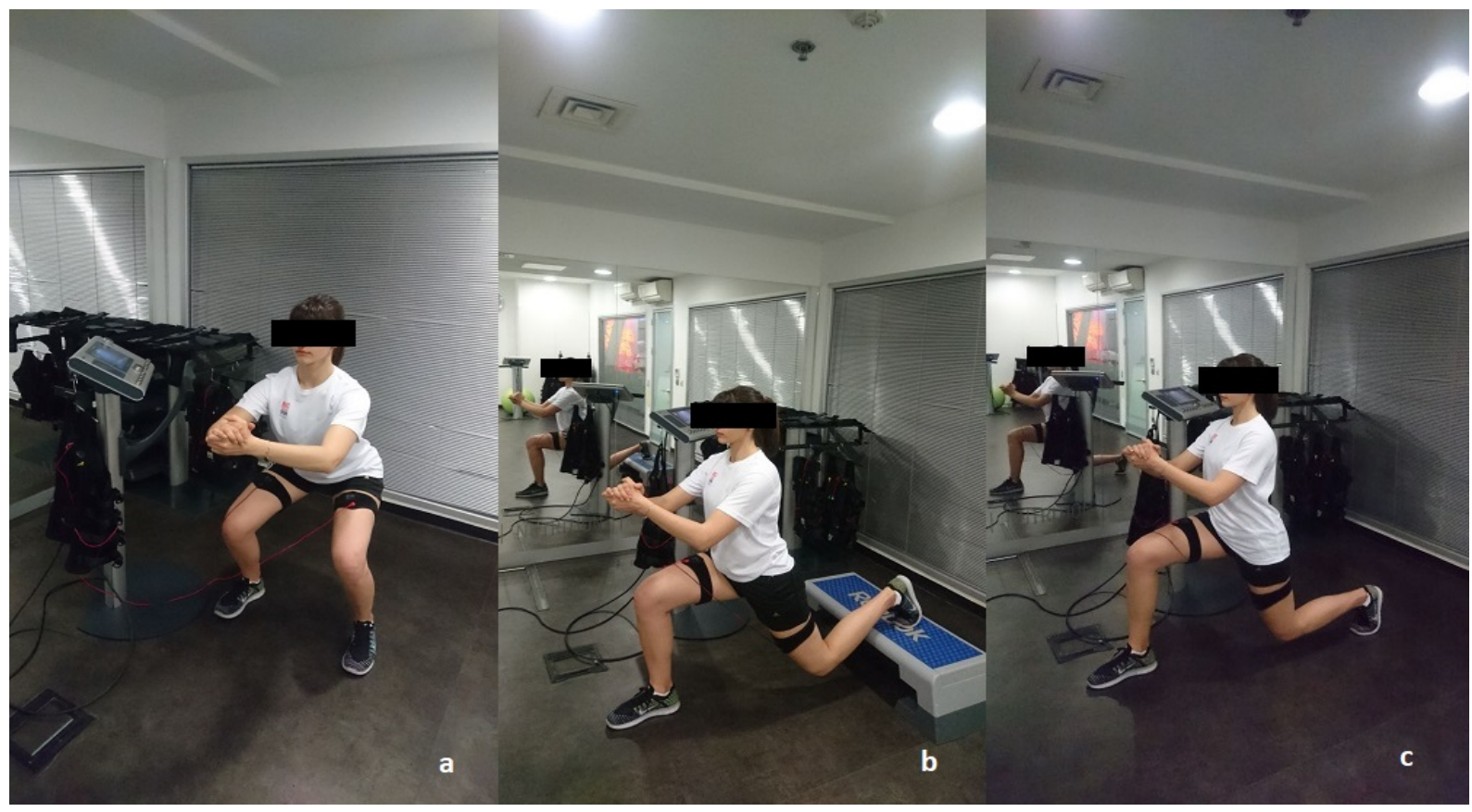

Figure 1. Leg movements and body position in calisthenic strength training. Squat (a), split squat (b) and lunge (c) are illustrated. 


\subsection{SWE and SMI Techniques}

Measurements were completed using an Aplio 500 Platinum ultrasound device (Toshiba Medical Systems, Japan) and high-frequency linear probe (frequency range 5-14 MHz). The measurements were completed by an experienced pediatric radiologist with more than 5 years of SWE and 2 years of SMI experience. The measurement location for RF was determined based on previous studies [17-18] .The same location was used for both SWE and SMI examinations. RF was examined at the midpoint between the lateral epicondyle of the femur, and the anterior superior iliac in supine position with the legs extended, and relaxed. This reference point was clearly marked on the skin with a pen. The transducer was placed in a longitudinal orientation along the muscle until a clear image of the fibers inside the muscle could be identified.

For SWE, the 2D-SWE map (left side) and quality mode (right side) were examined in split-screen mode. The quality mode, which is identified as the propagation mode (arrival time contour), is a mode in which reliable data is obtained when the lines are parallel and smooth, and the increase in the distance between the lines is parallel to the increase in elasticity. Subsequently, a 10x10 mm dimension "square region of interest (ROI)" was used to take measurements at three different points with three repeated acquisitions (Fig-2). The mean of the measured data points was calculated. For measurements, the elasticity modulus in kiloPascals (kPa: range $0-50)$ and shear wave velocity modulus in meters $/$ second $(\mathrm{m} / \mathrm{s}$ : range 0-8) were used.

SMI investigation used $>50 \mathrm{~Hz}$ frame rates. Pulse repetition frequency set was $220-234 \mathrm{~Hz}$ for SMI. The color gain was set to 30-40 decibels to suppress background artifacts. SMI imaging used color mode. The vascularity index (VI [\%]) measurement method was used to identify blood flow. In color mode, a rectangular ROI was manually drawn on a fixed window with $15 \times 10 \mathrm{~mm}$ dimensions. Within the ROI, the proportion of color pixels in the whole area was automatically calculated by the device in percentages to obtain vascularity index (\%) (VI) values including arterial and venous total vascularity supply (Fig-3).

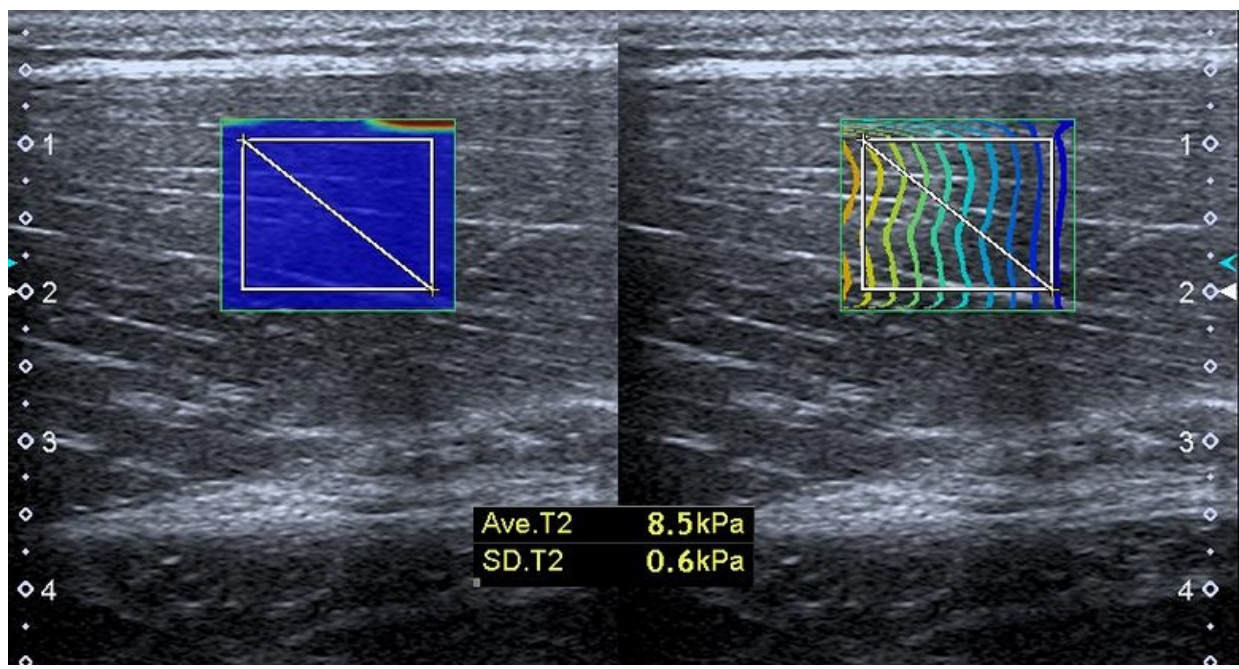

Figure 2. SWE measurement of RF was completed using a square ROI that was placed on homogeneous muscle parenchyma in longitudinal plane. 2D-SWE map (left side) and quality mode (right side) are seen. The measurement was recorded in kPa mode.

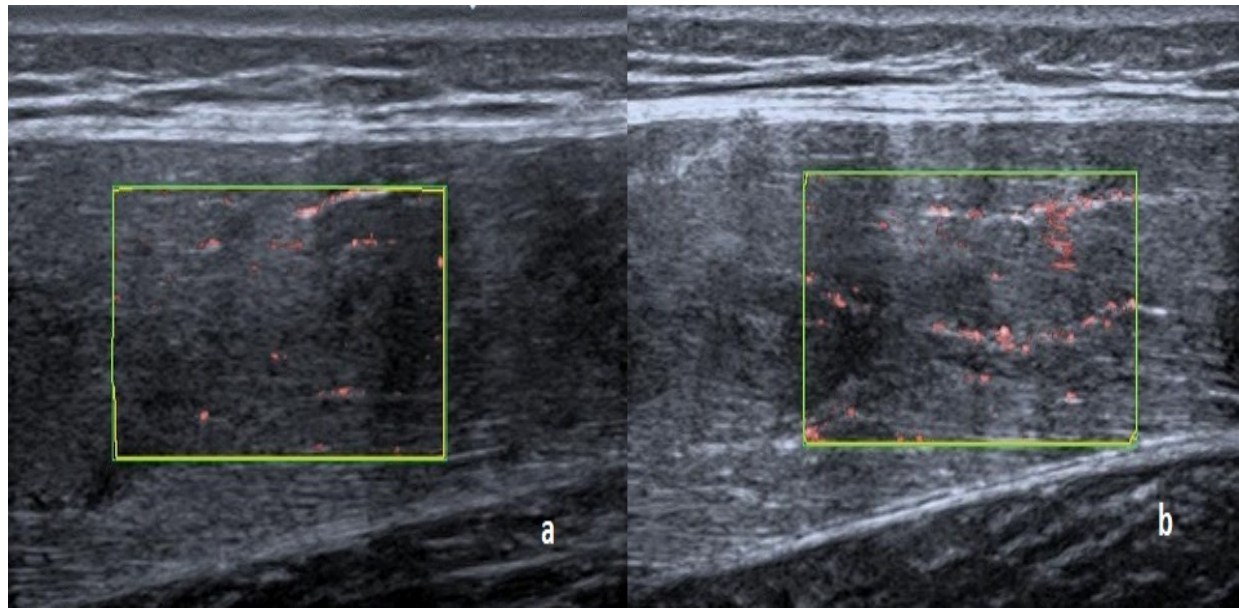

Figure 3. On SMI, an example demonstrating how strength exercises increase muscle blood flow. Clear variation is observed in RF VI (\%) in a subject using EMS for training before exercise (a) and after exercise (b). 


\subsection{Statistics}

Statistical analysis was performed with the SPSS (Statistical Package for the Social Sciences) program. Descriptive characteristics of the groups are given as minimum, maximum, mean and standard deviation. The difference in muscle stiffness and blood flow before and after training in the groups was assessed with the Wilcoxon test, a nonparametric test due to values not showing normal distribution. The differences within the groups were identified with the Mann Whitney U test. P values of less than 0.05 were considered statistically significant.

\section{Results}

The median age of all cases $(\mathrm{n}=20)$ was $21.4(17.4-29.2)$ years. The mean weight and height of all cases $(\mathrm{n}=20)$ were 69.86 (44.10-116.50) kilograms and 1.70 (1.52-1.86) meters, respectively.

When the values at rest and post-exercise are compared, in all cases there were significant increases in blood flow and stiffness in RF post-exercises $(\mathrm{p}<0.001)$ (resting mean VI [\%]: $1.42 \pm 0.58$ and post-exercise mean VI [\%]: $5.36 \pm$ 3.03; resting mean stiffness [kPa]: $8.85 \pm 1.38$ ) and post-exercise mean stiffness $[\mathrm{kPa}]: 10.57 \pm 1.79$ ) (Table-1).

In the group with EMS exercises, when resting (mean VI [\%]: $1.07 \pm 0.29$ ) and post-exercise (mean VI [\%]: 7.17 \pm 2.88 ) RF blood flow measurements and resting (mean $\mathrm{kPa}: 9.19 \pm 1.18$ ) and post-exercise (mean $\mathrm{kPa}: 11.35 \pm$ 1.73) RF stiffness measurements are compared, there were significant increases in blood flow and stiffness post-exercise (z: $-2.803 \mathrm{~b}$ p: 0.005 ; z: $-2.805 \mathrm{~b}$ p: 0.005 , respectively) (Table-2).

In the group with exercise but no EMS, when resting (mean VI [\%]: $1.77 \pm 0.59$ ) and post-exercise (mean VI [\%]: $3.55 \pm 1.97) \mathrm{RF}$ blood flow measurements and resting (mean kPa: $8.51 \pm 1.55)$ and post-exercise (mean kPa: $9.79 \pm 1.55) \mathrm{RF}$ stiffness measurements are compared, there were significant increases in blood flow and stiffness post-exercise (z: $-2.807 \mathrm{~b}, \mathrm{p}: 0.005$; z: $-2.807 \mathrm{~b}$, p: 0.005, respectively) (Table-2).

Table 1. Differences in resting and post-exercise measurements of blood flow and stiffness in the all subjects

\begin{tabular}{|c|c|c|c|c|c|c|}
\hline$n=20$ & mean & standard deviation & minimum & maximum & z & $\mathrm{p}$ \\
\hline Resting VI (\%) & 1.42 & 0.58 & 0.70 & 2.50 & \multirow{2}{*}{$-3.922^{b}$} & \multirow{2}{*}{$<0.001$} \\
\hline Post-exercise VI (\%) & 5.36 & 3.03 & 1.5 & 12.00 & & \\
\hline Resting stiffness kpa & 8.85 & 1.38 & 6.90 & 12.10 & \multirow{2}{*}{$-3.922^{b}$} & \multirow{2}{*}{$<0.001$} \\
\hline Post-exercise stiffness kpa & 10.57 & 1.79 & 7.60 & 14.00 & & \\
\hline
\end{tabular}

$\mathrm{n}$ : number of subjects, VI: vascularity index, kPa: kiloPascal

Bold values depict significant difference.

Table 2. Difference between resting and post-exercise measurements in the groups with and without EMS in terms of blood flow and stiffness

\begin{tabular}{|c|c|c|c|c|c|c|c|}
\hline & $n=20$ & mean & $\begin{array}{c}\text { standard } \\
\text { deviation }\end{array}$ & $\min$ & $\max$. & z & $\mathrm{p}$ \\
\hline \multirow{4}{*}{$\begin{array}{c}\text { With EMS } \\
n=10\end{array}$} & Resting VI (\%) & 1.07 & 0.29 & 0.70 & 1.60 & \multirow{2}{*}{$-2.803^{b}$} & \multirow{2}{*}{0.005} \\
\hline & Post-exercise VI (\%) & 7.17 & 2.88 & 2.00 & 12.00 & & \\
\hline & Resting stiffness & 9.19 & 1.18 & 7.60 & 10.90 & \multirow{2}{*}{$-2.805^{\mathrm{b}}$} & \multirow{2}{*}{0.005} \\
\hline & Post-exercise stiffness & 11.35 & 1.73 & 8.50 & 14.00 & & \\
\hline \multirow{4}{*}{$\begin{array}{c}\text { Without EMS } \\
\quad n=10\end{array}$} & Resting VI (\%) & 1.77 & 0.59 & 0.80 & 2.50 & \multirow{2}{*}{$-2.807^{b}$} & \multirow{2}{*}{0.005} \\
\hline & Post-exercise VI (\%) & 3.55 & 1.97 & 1.50 & 8.60 & & \\
\hline & Resting stiffness & 8.51 & 1.55 & 6.90 & 12.10 & \multirow{2}{*}{$-2.807^{\mathrm{b}}$} & \multirow{2}{*}{0.005} \\
\hline & Post-exercise stiffness & 9.79 & 1.55 & 7.60 & 13.00 & & \\
\hline
\end{tabular}

EMS: electromyostimulation, max: maximum, min: minimum, n: number of subjects, VI: vascularity index, kPa: kiloPascal

Bold values depict significant difference. 
Comparing the post-exercise RF VI (\%) and RF stiffness values in the groups with EMS and without EMS exercises, there was a significant difference between the groups (Fig-4).

The blood flow and stiffness values in the group with EMS exercises had greater increases compared to the group without EMS ( $\mathrm{p}=0.007, \mathrm{p}=0.05$, respectively) (Table-3).

\section{Discussion}

This study was completed with the aim of investigating the acute effect of calisthenic strength exercises combined with EMS and calisthenic strength exercises without EMS on RF blood flow and stiffness. According to the results of the study, in both groups with EMS and without, blood

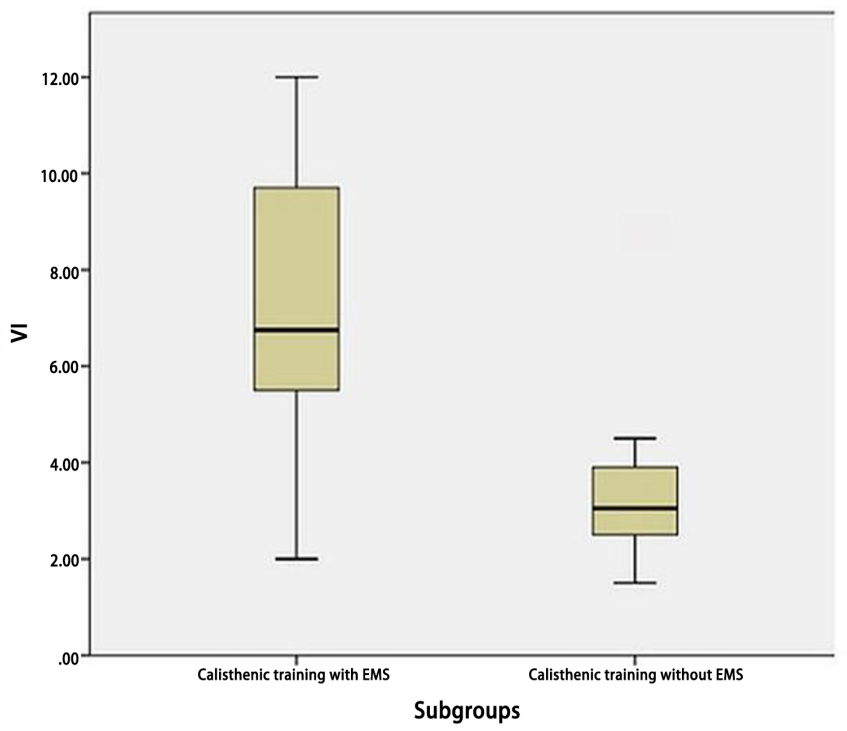

flow and stiffness increased after exercise. However, the group with EMS exercises had greater increases in blood flow and stiffness compared to the group without EMS.

Previous studies related to EMS focused on muscle strength, muscle volume, nervous system and rehabilitation after sports injury with EMS. Among these, the majority of studies about EMS are related to muscle strength. Based on studies showing EMS training increases voluntary muscle strength and muscle volume, this training method began to be intensely included in strength training plans. In relation to resistance training, EMS training increases the muscle cross-section and increases maximum voluntary muscle strength [19]. However, there are studies stating that the increase in strength with EMS strength exercises is not greater than the increase in strength with classic strength exercises $[19,20]$.

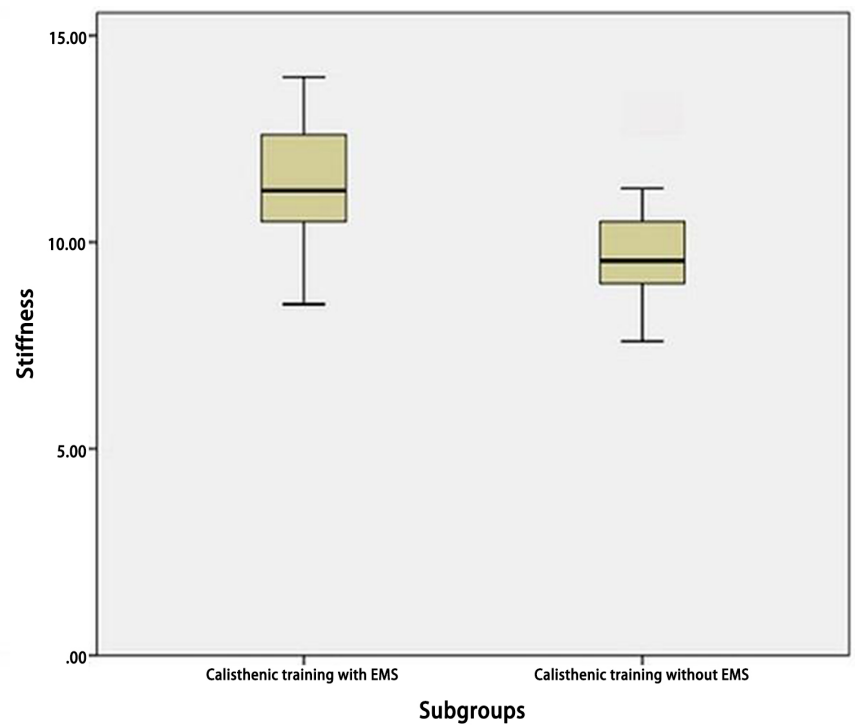

Figure 4. The mean blood flow and stiffness obtained with calisthenic strength training with EMS was significantly higher than the mean blood flow and stiffness obtained with calisthenic strength training without EMS.

Table 3. Comparing the post-exercise RF blood flow and RF stiffness differences in the groups with EMS and without EMS exercises.

\begin{tabular}{|c|c|c|c|c|c|c|c|}
\hline & $n=20$ & mean & standard deviation & $\min$. & $\max$ & z & $\mathrm{p}$ \\
\hline \multirow{2}{*}{ Stiffness } & $\begin{array}{c}\text { With EMS } \\
n=10\end{array}$ & 11.35 & 1.73 & 8.50 & 14.00 & \multirow[b]{2}{*}{-1.854} & \multirow[b]{2}{*}{0.05} \\
\hline & $\begin{array}{c}\text { Without EMS } \\
n=10\end{array}$ & 9.79 & 1.55 & 7.60 & 13.00 & & \\
\hline \multirow{2}{*}{ VI (\%) } & $\begin{array}{c}\text { With EMS } \\
n=10\end{array}$ & 7.17 & 2.88 & 2.00 & 12.00 & \multirow[b]{2}{*}{-2.686} & \multirow[b]{2}{*}{0.007} \\
\hline & $\begin{array}{c}\text { Without EMS } \\
n=10\end{array}$ & 3.55 & 1.97 & 1.50 & 8.60 & & \\
\hline
\end{tabular}

EMS: electromyostimulation, max: maximum, min: minimum, n: number of subjects, VI: vascularity index

Bold values depict significant difference. 
Intramuscular perfusion is accepted as an important parameter in sporting performance and physical fitness. It has been proven in previous studies that physically active individuals have better blood flow and vascular diameters compared to sedentary individuals $[10,11]$. When studies related to blood flow are investigated, after 4 weeks of applied strength exercises, there were increases in superficial femoral and carotid artery diameter and blood flow. After stopping training, the blood flow and arterial diameters return to normal values [21]. After acute EMS training in spinal cord injury patients, leg perfusion was found to increase [5]. It was found that vibration training increased blood flow and that EMS applied to leg muscles with combined vibration training increased calf perfusion [22-24]. Labrunée et al reported that EMS is able to directly reduce sympathetic activity in patients with chronic heart failure. They also showed that this putative beneficial effect linked to a sensory stimulation was preserved while chronic heart failure patients were exposed to EMS, the latter combining sensory and muscular stimulation [25]. Kemmler et al concluded that EMS appears to be an effective training tool for reducing low back pain [26]. Bruce et al mentioned that home-based EMS was an acceptable alternative to exercise therapy in the management of knee osteoarthritis, producing similar improvements in functional capacity [27]. Similar to these studies, our study found that strength training with and without EMS increased acute RF blood flow. Different to these studies, the variation in muscle blood flow was investigated in detail with the novel radiological method of SMI. From this aspect, our study is unique. Additionally, according to our results, the muscle blood flow increase values in the group with EMS and exercise were found to be higher than in the group with exercise but no EMS. These results show that EMS exercise increases muscle blood flow more and may be beneficial for athletic performance.

The number of studies about muscle stiffness using the SWE method is very few compared to other organs in the body. Additionally, the studies investigating the association between muscle stiffness and athletic performance are insufficient. In this study, the relationship between passive muscle stiffness on athletic performance in adolescent female basketball players was investigated and there was no correlation found between vertical jumping and oxygen use capacity with muscle stiffness. It is not known how acute and chronic training affect muscle stiffness in sedentary individuals and sportspeople. At the end of our study, there was an increase found in muscle stiffness in the hyperacute period after strength exercises both with and without EMS. However, the increase in muscle stiffness among those with EMS exercises was greater compared to those exercising without EMS. This result shows that acute strength training increases muscle stiffness. When these strength exercises are combined with EMS training, it is more effective on muscle stiffness.
There is a need for more comprehensive studies to investigate the chronic effects of exercises using EMS on athletic performance.

There are some limitations to our study. The first is the low number of subjects. Another limitation is that the study only investigated variations in blood flow and stiffness in a single muscle (rectus femoris). Additionally, the study only investigated the acute effects on the muscle, with long-term effects of training not investigated.

\section{Conclusions}

In conclusion, strength exercises increased blood flow and stiffness of the RF muscle in the acute period. Strength exercises combined with EMS increased muscle blood flow and stiffness more compared to classic exercise methods. As a result, strength exercises completed using EMS may be more beneficial for good athletic performance. Future studies will investigate the chronic effects of EMS combined with calisthenics strength exercises.

\section{Conflict of Interest}

The authors declare that none of them has any conflict of interest.

\section{Acknowledgements}

We acknowledge Mr. Ibrahim Adaletli for his assistance in the online literature search.

\section{REFERENCES}

[1] Kale M, Kaçoglu C, Gürol B. The Effects of Electromyostimulation Training on Neural Adaptation and Sports Performance, H.J.S.S,25:142-158, 2014

[2] Marqueste T, Hug F, Decherchi P, et al. Changes in neuromuscular function after training by functional electrical stimulation. Muscle Nerve,28:181-188, 2003

[3] Enoka RM. Muscle strength and its development: new perspectives. Sports Med, 6:146-168, 1988

[4] Kemmler W, Weissenfels A, Bebenek M, et al. Effects of Whole-Body Electromyostimulation on Low Back Pain in People with Chronic Unspecific Dorsal Pain: A Meta-Analysis of Individual Patient Data from Randomized Controlled WB-EMS Trials. J Evid Based Complementary. Altern Med 2017. Doi: 10.1155/2017/8480429.

[5] Menéndez H, Ferrero, C, Martín-Hernández J, et al. Acute effects of simultaneous electromyostimulation and vibration on leg blood flow in spinal cord injury. Spinal Cord, 54.5:383, 2016. 
[6] Filipovic A, Grau M, Kleinöder $\mathrm{H}$, et al. Effects of a whole-body electrostimulation program on strength, sprinting, jumping, and kicking capacity in elite soccer players. Med Sci Sports Exerc, 15:639, 2016.

[7] Mathes S, Lehnen N, Link T, et al. Chronic effects of superimposed electromyostimulation during cycling on aerobic and anaerobic capacity. Eur. J. Appl. Physiol, 117:881-892, 2017.

[8] Ernst AT, Jensen RL. 7-weeks of yoga training and its effects on flexibility and rate of force development in olympic weightlifters. ISBS, 34:585-588, 2016.

[9] Silinskas V, Grunovas A, Stanislovaitiene J, et al. Effect of Electrical Myostimulation on the Function of Lower Leg Muscles. J Strength Cond Res, 31:1577-1584, 2017.

[10] Dinenno FA, Tanaka H, Monahan KD, et al. Regular endurance exercise induces expansive arterial remodelling in the trained limbs of healthy men. J Physiol, 534:287-295, 2001.

[11] Huonker M, Schmid A, Schmidt-Trucksass A, et al. Size and blood flow of central and peripheral arteries in highly trained able-bodied and disabled athletes. J Appl Physiol, 95:685-691, 2003.

[12] Miyachi M, Tanaka H, Yamamoto K, et al. Effects of one-legged endurance training on femoral arterial and venous size in healthy humans. J Appl Physiol, 90:2439-2444, 2001

[13] Bleeker MW, De Groot PC, Rongen GA, et al. Vascular adaptation to deconditioning and the effect of an exercise countermeasure: results of the Berlin Bed Rest study. J Appl Physiol, 99:1293-1300, 2005.

[14] Sugawara J, Hayashi K, Kaneko F, et al. Reductions in basal limb blood flow and lumen diameter after shortterm leg casting. Med Sci Sports Exerc, 36:1689-1694, 2004.

[15] Bassett D, Howley E. Limiting factors for maximum oxygen uptake and determinants of endurance performance. Med Sci Sports Exerc, 32:70-84, 2000.

[16] Machado P, Segal S, Lyshchik A, et al. Novel microvascular flow technique: initial results in thyroids. Ultrasound Q, 32:67-74, 2016.

[17] Chino K, Ohya T, Kato E, et al. Muscle Thickness and Passive Muscle Stiffness in Elite Athletes: Implications of the Effect of Long-Term Daily Training on Skeletal Muscle.
Int J Sports Med, 39:218-224,2018.

[18] Taş S, Onur MR, Y1lmaz S, et al. Shear Wave Elastography Is a Reliable and Repeatable Method for Measuring the Elastic Modulus of the Rectus Femoris Muscle and Patellar Tendon. J Ultrasound Med, 36:565-570 2017.

[19] Holcomb WR. Effect of training with neuromuscular electrical stimulation on elbow flexion strength. J Sports Sci Med, 5:276-281, 2006.

[20] Maffiuletti NA. Physiological and methodological considerations for the use of neuromuscular electrical stimulation. Eur J Appl Physiol, 110:223-234, 2010.

[21] Stebbings GK, Morse C I, McMahon GE, et al. Resting arterial diameter and blood flow changes with resistance training and detraining in healthy young individuals. J Athl Train, 48:209-219, 2013.

[22] Lohman IIIEB, Petrofsky J S, Maloney-Hinds C, et al. The effect of whole body vibration on lower extremity skin blood flow in normal subjects. Med Sci Monit, 13:71-76, 2007.

[23] Lohman IIIEB, Sackiriyas KSB, Bains GS, et al. A comparison of whole body vibration and moist heat on lower extremity skin temperature and skin blood flow in healthy older individuals. Med Sci Monit, 18:415, 2012.

[24] Vanderthommen M, Depresseux JC, Dauchat L, et al. Blood flow variation in human muscle during electrically stimulated exercise bouts. Arch Phys Med Rehabil, 83:936-941, 2002.

[25] Labrunée M, Despas F, Marque P, Guiraud T, Galinier M, Senard JM et al. Acute electromyostimulation decreases muscle sympathetic nerve activity in patients with advanced chronic heart failure (EMSICA Study). PLoS One, 8(11):e79438. 2013.

[26] Kemmler W, Weissenfels A, Bebenek M, Fröhlich M, Kleinöder $\mathrm{H}$, Kohl $\mathrm{M}$ et al. Effects of Whole-Body Electromyostimulation on Low Back Pain in People with Chronic Unspecific Dorsal Pain: A Meta-Analysis of Individual Patient Data from Randomized Controlled WB-EMS Trials. Evidence-Based Complementary and Alternative Medicine 2017.

[27] Bruce-Brand RA, Walls RJ, Ong JC, Emerson BS, O'Byrne JM, Moyna NM. Effects of home-based resistance training and neuromuscular electrical stimulation in knee osteoarthritis: a randomized controlled trial. BMC musculoskeletal disorders, 13(1):118, 2012. 